PONTIFÍCIA UNIVERSIDADE CATÓLICA DO RIO DE JANEIRO

Percepção da Sustentabilidade sob o Olhar de Donos de Bares e Restaurantes durante a Pandemia de Covid-19

\author{
João Pedro Basso
}

Trabalho de Conclusão de CuRso

Centro de CIÊnCIAS SOCIAIS - CCS

DEPARTAMENTO dE AdMINISTRAÇÃO Graduação em Administração de Empresas 
João Pedro Basso

\section{Percepção da Sustentabilidade sob o Olhar de Donos de Bares e Restaurantes durante a Pandemia de Covid-19}

Trabalho de Conclusão de Curso, apresentado ao programa de graduação em Administração da PUC-Rio como requisito parcial para a obtenção do titulo de graduação em Administração.

Orientador(a): Daniel Kamlot

Rio de Janeiro

Novembro de 2020. 


\section{Agradecimentos}

Agradeço primeiramente a minha família, minha irmã, meu pai e minha mãe por me fornecerem a oportunidade de realizar a graduação e sempre me dando força para continuar. Agradeço também meus grandes amigos que junto comigo passaram por todas as jornadas dentro da graduação, Daniel Garbelote, Christian Bittencourt, Gabriel Torquato, Matheus Bernal e Luiz Felippe Perin Basso. 


\section{Resumo}

Basso, João Pedro. Percepção de Sustentabilidade sob o olhar de Donos de Bares e Restaurantes durante a Pandemia de COVID-19. Rio de Janeiro, 2020. Número de páginas p.40. Trabalho de Conclusão de Curso

- Departamento de Administração. Pontifícia Universidade Católica do Rio de Janeiro.

Sustentabilidade é um tema que vem cada vez mais aparecendo, não só nas mídias como também em práticas efetivas no mercado em diversos setores. O setor de bares e restaurantes também vem mudando, com o mercado, gradualmente exigindo ações sustentáveis. Com o advento da pandemia de COVID-19, porém, houve uma aceleração de certas tendências, algumas delas contribuindo para uma gestão sustentável. Devido a isso, com novas exigências no sentido sustentável, o entendimento sobre o tema de indivíduos com poder de decisão em bares e restaurantes é um fator essencial para ocorrer mudanças significativas em direção a um gerenciamento sustentável completo.

\section{Palavras- chave}

Sustentabilidade, Bares e Restaurantes, Pandemia, COVID-19, Percepção

\section{Abstract}

Basso, João Pedro. Perception of Sustainability under the eyes of Bar and Restaurant Owners during COVID-19 Pandemic. Rio de Janeiro, 2020. Número de páginas p.40. Trabalho de Conclusão de Curso Departamento de Administração. Pontifícia Universidade Católica do Rio de Janeiro.

Sustainability is a theme that is increasingly appearing, not only in the media but also in effective practices in the market in several sectors. The bar and restaurant sector has also been changing, with the market gradually demanding sustainable actions. With the advent of the COVID-19 pandemic, however, certain trends accelerated, some of them contributing to a sustainable management. Because of this, with new demands in a sustainable sense, the understanding of individuals with decision-making power about sustainability in bars and restaurants is an essential factor for significant changes towards a complete sustainable management.

\section{Key-words}

Sustainability, Restaurant, Pandemic, COVID-19, Perception 


\section{Sumário}

1 . Introdução

1.1. Objetivo Final 2

1.2. Objetivos Intermediários 2

1.3. Delimitação do Estudo 3

1.4. Justificativa do Estudo 3

2. Referencial Teórico 4

2.1. Sustentabilidade 4

2.2. Sustentabilidade em bares e restaurantes 5

2.2.1. Gestão Ambiental 5

2.2.2. Cadeia de Suprimentos Sustentável 6

2.2.3. Responsabilidade Social Empresarial 6

2.3. Percepção

2.4. Pandemia de COVID-19 8

2.4.1. Auxílio Governamental 9

2.4.2. Plano de Retomada Econômica e Restrições 10

2.4.3. Tendências Sustentáveis 12

3. Metodologia 13

3.1. Tipo de pesquisa 13

3.2. Seleção de sujeitos $\quad 13$

3.3. Coleta de dados 14

3.4. Tratamento dos dados 16

3.5. Limitações do método 16

4. Análise de Resultados 17

4.1. Perfil dos Entrevistados e Empreendimentos 17

$\begin{array}{lr}\text { 4.2. Entrevistas } & 18\end{array}$

5. Conclusão 26

6. Referências Bibliográficas 30 


\section{Lista de llustrações}

Figura 1 - Resumo das atividades classificadas...........................................10

Figura 2 - Regras de ouro da reabertura no Rio............................................11

Figura 3 - Perguntas introdutórias...............................................................14

Figura 4 - Perguntas feita aos entrevistados..............................................15

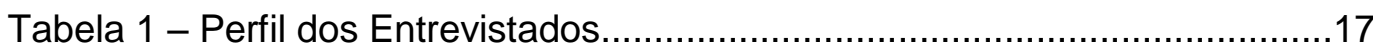

Tabela 2 - Perfil dos Empreendimentos......................................................18 


\section{Introdução}

A sustentabilidade é um termo que vem ganhando cada vez mais importância e significados para a sociedade atual. A humanidade como um todo começou a desenvolver consciência de que os recursos dos quais somos fortemente dependentes não são infinitos ou imutáveis, e utilizá-los de forma desenfreada pode provocar efeitos globais catastróficos duradouros. Apesar de sustentabilidade ser um tema comumente visto como algo holístico, a sua prática em esferas do dia-a-dia pode efetivar uma diferença relevante, se adotada por grande parte das pessoas e organizações.

O aumento da relevância da sustentabilidade afeta diretamente as novas tendências de consumo, principalmente da geração Z (nascidos entre 1996 e 2010) que já chega a representar aproximadamente $40 \%$ dos consumidores do mercado de sustentabilidade segundo o Relatório de Inteligência do Sebrae/SC (2020).

Com o advento da pandemia de Covid-19 e seus efeitos, o setor de serviços sofreu bastante, segundo Alvarenga (2020), este setor teve queda recorde de $9,7 \%$ no 20 trimestre de 2020 . O ramo de bares e restaurantes especificamente, ainda segundo Alvarenga (2020), foi uma das atividades mais prejudicadas por demandar atendimento presencial. Desse modo forçando este ramo a se readequar a certas práticas a fim de se adequar a uma nova realidade.

A pandemia de Covid-19 acabou por acelerar algumas tendências sustentáveis e levantou ainda mais a importância dessas práticas. Segundo o Relatório de Inteligência do SEBRAE/SC (2020), tendências de aumento do consumo de produtos vegetarianos e adoção de práticas de informar o consumidor e realizar iniciativas relativas à sustentabilidade têm crescido durante a crise pandêmica.

No Brasil, estima-se que o setor de bares e restaurantes represente 2,7\% do PIB nacional (SEBRAE, 2017) e, segundo a Agência Brasil (2020), há cerca de 15 mil bares e restaurantes associados à Abrasel (Associação Brasileira de Bares e Restaurantes) no Estado do Rio de Janeiro, sendo 10 mil só na capital. Considerando a relevância do setor com uma média de crescimento nos últimos 
dez anos de $11,5 \%$ ao ano (ABIA, 2019) e também os novos desafios e tendências causados pela pandemia de Covid-19, qual a percepção de proprietários de pequenos e médios bares e restaurantes sobre a sustentabilidade?

\subsection{Objetivo Final}

Este estudo pretende avaliar a percepção da importância da sustentabilidade durante o surto de Covid-19 sob o ponto de vista de proprietários de pequenos e médios negócios do setor de bares e restaurantes no município do Rio de Janeiro.

\subsection{Objetivos Intermediários}

- Identificar ações sustentáveis adequadas para bares e restaurantes

- Apresentar o mercado de bares e restaurantes na situação atual, e as consequências advindas da pandemia de Covid-19 


\subsection{Delimitação do Estudo}

O estudo está delimitado à análise somente da percepção dos donos de bares e restaurantes formais de médio e pequeno portes das zonas sul, oeste e central do município do Rio de Janeiro.

A classificação do porte das empresas será o critério usado pelo BNDES:

Empresas de pequeno porte são aquelas com faturamento anual maior que $R \$$ 360 mil e menor ou igual a $R \$ 4,8$ milhões, e empresas de médio porte apresentam faturamento anual maior que $\mathrm{R} \$ 4,8$ milhões e menor ou igual a $\mathrm{R} \$$ 300 milhões.

\subsection{Justificativa do Estudo}

Este estudo fornecerá dados da percepção de indivíduos com poder de decisão em bares e restaurantes sobre o tema sustentabilidade durante a crise de Covid-19. A noção dessa percepção pode ser útil para qualquer organização que deseja conscientizar esse público em relação à importância do tema, ou que almeje vender algum produto ou serviço relacionado ao tema. Com isso, o estudo irá expor possíveis definições e conceitos incorretos que podem existir no entendimento desse segmento. 


\section{Referencial Teórico}

\subsection{Sustentabilidade}

O termo sustentabilidade vem cada vez mais ganhando destaque no cenário mundial. Gradualmente começamos a ver um aumento de notícias relacionadas à desastres ocasionados, diretamente e indiretamente, por uma gestão, tanto em nível individual até níveis governamentais, parcialmente ausente de ações sustentáveis. Com isso, ter conhecimento do que significa este termo é essencial para que entendamos como cessar esses "maus hábitos".

Segundo Torresi, Pardini e Ferreira (2010, p. 1) grande parte das pessoas tem a percepção de que sustentabilidade tem relação apenas com emissão de gases estufa, como o gás carbônico e que esse é a única ameaça a Terra. Porém isso é impreciso, na realidade este é um dos principais problemas, mas não o único.

Sobre sustentabilidade,

[...] ela fundamentalmente significa: o conjunto dos processos e ações que se destinam a manter a vitalidade e a integridade da Mãe Terra, a preservação de seus ecossistemas com todos os elementos físicos, químicos e ecológicos que possibilitam a existência e a reprodução da vida, o atendimento das necessidades da presente e futuras gerações, e a continuidade, a expansão e a realização das potencialidades da civilização humana em suas várias expressões. (BOOF, 2017, p.34).

Resumidamente, o conceito de sustentabilidade pode ser definido pelo significado do triple bottom line. Segundo o conceito de Porter e Kramer (2006), o triple bottom line consiste no empenho em crescimento da organização e sua continuidade no mercado, visando à sua viabilidade econômica e convivência harmônica com a sociedade e meio ambiente. 


\subsection{Sustentabilidade em bares e restaurantes}

No setor de bares e restaurantes existem diversas ações consideradas como sustentáveis que direcionam a gestão a um rumo que, além de gerar impactos socioambientais positivos, também geram aumento de lucratividade. As práticas sustentáveis se situam desde uma boa gestão ambiental, de recursos humanos até a preocupação com sua cadeia produtiva, ou seja, está presente em várias áreas do gerenciamento de bares e restaurantes.

\subsubsection{Gestão Ambiental}

Gestão ambiental, segundo Moretti, Sautter e Azevedo (2008), configura um conjunto de ações aplicadas com intuito de controle e diminuição de impactos causados por uma organização ao meio ambiente. Na realidade do setor de bares e restaurantes, isso pode ser expresso na economia de energia e água e principalmente gestão de resíduos.

Em relação à economia de água, para bares e restaurantes, a melhor forma de economizar esse recurso é em seu uso eficiente e reutilização, quando possível. Segundo o SEBRAE (2016, p.17) pode haver até 50\% de economia de água com a instalação de acionadores duplos nas descargas de vasos sanitários, além disso, sistemas de captação de chuva podem contribuir ainda mais, possibilitando o uso dessa água para privadas, lavanderia, lavagem de áreas comuns e ainda para sistemas de resfriamentos.

O uso eficiente de energia elétrica também é fundamental para seguir um rumo sustentável na gestão de um bar ou restaurante. Além do próprio benefício de economizar a energia, pode diminuir significativamente os custos com esse consumo. Segundo a Green Restaurant Association (2018), as áreas em que deve haver foco para economia de energia são em sistemas de resfriamento (ar condicionado), ventilação, iluminação, equipamentos de refrigeração e cozimento, aquecimento da água e até em produção de energia limpa (placas solares). Segundo o SEBRAE (2016, p.20), algumas ações praticáveis são: instalação de placas fotovoltaicas para produção de energia e aquecimento da água; realizações de inspeções periódicas na rede elétrica, com intuito de verificar a necessidade de troca de equipamentos ineficientes; e boa gestão de estoque de alimentos, pois o armazenamento inadequado pode alterar as propriedades da comida e desperdiçar energia. 
A gestão de resíduos é uma das atividades mais importantes no universo de gerenciamento de um restaurante. De acordo com o SEBRAE (2016, p.18), 150 mil toneladas de lixo são produzidas, anualmente, por um restaurante médio. Essa quantidade pode ser reduzida, por meio de um redesenho dos processos de produção, tendo como prioridades evitar desperdícios, reutilizar e reciclar; e um sistema de controle de sobras, para que se verifique a sua principal causa.

Além disso, existem iniciativas estaduais no Rio de Janeiro que contribuem positivamente para a questão de resíduos em restaurantes, é o caso do PROVE (Programa de Reaproveitamento de Óleos Vegetais), criado em 2008. Segundo Santos, Martinazzo e De Freitas (2018), o PROVE objetiva evitar o despejo do óleo de cozinha em corpos hídricos, estimulando sua coleta para a produção de sabão e de fontes alternativas de energia.

\subsubsection{Cadeia de Suprimentos Sustentável}

A gestão de cadeia de suprimentos sustentável tem em vista a eficiência de gerenciamento dos processos no decorrer das cadeias, levando em conta fatores econômicos e de competitividade, como também aspectos socioambientais (BESKE, 2012).

Nos bares e restaurantes, a forma mais adequada de garantir um bom gerenciamento sustentável de suas cadeias é conhecer a cadeia produtiva para saber se seus fornecedores possuem boas práticas de gestão.

\footnotetext{
Uma cadeia produtiva sustentável começa com o estabelecimento de um sistema de compras sustentáveis. Não basta olhar apenas o preço e a qualidade dos produtos. Nesse sentido, é fundamental saber como suas matérias-primas são produzidas e distribuídas. (SEBRAE, 2016, p.14).
}

Desse modo, indiretamente, o próprio restaurante pode acabar servindo como um encorajamento inicial para que seus fornecedores comecem a adotar práticas sustentáveis.

\subsubsection{Responsabilidade Social Empresarial}

A responsabilidade social compreende ações empresariais que tragam benefícios para a sociedade, forneça a possibilidade de conquista profissional 
aos contratados diretos, proporcione ganhos aos parceiros, impacto positivo ao meio ambiente, e produza retorno aos investidores (DOS SANTOS, 2008).

$\mathrm{Na}$ perspectiva de bares e restaurantes, segundo a ABRASEL (2019), a maioria das médias e pequenas organizações não incorpora a responsabilidade social como um objetivo, geralmente entendendo isso como um aumento de custos. Porém, existem ONGs que juntamente com restaurantes realizam trabalho social significativo, como é o caso da ONG espanhola "Acción contra el Hambre" (Ação contra Fome). Esta realiza ações em diversos países com dinheiro vindo de restaurantes membros, em que parte da renda de cada pedido de pratos cadastrados é direcionado aos projetos da ONG (ACCIÓN CONTRA EL HAMBRE, 2020).

Algumas formas independentes de realizar condutas de responsabilidade social podem ser a simples inserção de pratos da culinária local, valorizando sua cultura; disponibilização do estabelecimento para eventos feitos pela comunidade, fora do horário de funcionamento; e até a dedicação, juntamente com outros empreendimentos locais, para a melhoria do espaço público através de financiamentos em conjunto (SEBRAE, 2016).

\subsection{Percepção}

Segundo Solomon (2011), a percepção é a sequência pela qual as sensações são separadas, organizadas e interpretadas. Os fatores externos, como a cultura, crença, ideologia, as vontades e necessidades são elementos que podem influenciar na percepção do indivíduo.

Os meios de informação e comunicação são grandes influenciadores de opinião. A opinião é um componente da percepção, principalmente se abordarmos conceitos ou definições acerca de um tema. Notícias e informações vindas de uma fonte considerada confiável pelo indivíduo têm o poder de alterar ou redefinir sua opinião.

A satisfação é um dos modos de expressar a percepção sobre algo. "Satisfação consiste na sensação de prazer ou desapontamento resultantes da comparação do desempenho (ou resultado) percebido de um produto em relação às expectativas do comprador" (KOTLER, 2000, p.58). É possível afirmar que consumidores que possuem preocupação com sustentabilidade, irão ter maior preferência em obter o produto ou serviço de uma organização que sabidamente possui práticas sustentáveis em sua operação e que as transparece ao público. 
Ou seja, ter o conhecimento de que a organização possui efetivamente práticas sustentáveis pode influir diretamente na satisfação do cliente.

A percepção em relação à sustentabilidade, como qualquer outro tema, é influenciada não só pelas sensações e interpretações do indivíduo, mas também por vários fatores externos, como já dito anteriormente. Um estudo realizado na Argentina por Johnson et al. (2015) avaliou a percepção de moradores que residem ao longo de um rio pertencente a uma das bacias hidrográficas mais poluídas da região de Buenos Aires. Por terem contato frequente com a poluição, os resultados mostraram que a percepção da população foi altamente influenciada pelo que eles viam e sentiam. Ou seja, em um local que não tenha um "objeto" que visivelmente mostre as consequências de uma gestão não sustentável, a população local pode vir a deduzir que práticas sustentáveis podem ser um exagero ou desnecessárias.

Outro estudo de caso, realizado por Vicenzi et al. (2017) no Estado do Paraná, analisou a percepção sobre sustentabilidade da população localizada na Bacia Hidrográfica do Rio Paraná 3, a oeste do Estado, e concluiu que seus habitantes têm um baixo nível de percepção sobre o tema e a dimensão prevalecente foi a ambiental. A maior parte dos entrevistados pertencem ao segmento urbano da região, e apesar do estudo ser no Estado do Paraná, a probabilidade do resultado encontrado ser similar em outras regiões urbanas do país, é considerável. Portanto, com um evento de grandes consequências econômicas e de saúde, a pandemia de COVID-19, pode interferir na percepção sobre sustentabilidade.

\subsection{Pandemia de COVID-19}

A pandemia global de COVID-19 é algo inédito, na proporção que alcançou, na história humana. Segundo a notícia da Agência Brasil (2020), no início de outubro de 2020, o Brasil era o $3^{\circ}$ país com maior número de casos no mundo e o $2^{\circ}$ com maior número de óbitos por COVID-19. Com a grande incidência do vírus no país, os impactos na área de saúde, política, econômica e social foram enormes.

As medidas tomadas para frear a propagação do vírus, como restrições de mobilização e viagens, quarentena e distanciamento social resultaram no fechamento temporário de negócios de hospitalidade e diminuíram drasticamente sua demanda (BARTIK et al., 2020). Com o processo de abertura 
lentamente ocorrendo, bares e restaurantes têm tido imposições referentes aos cuidados contra a disseminação do vírus, tanto para funcionários quanto para clientes, as quais os obrigará a fazer mudanças substanciais para se manterem (GÖSSLING et al., 2020).

No Brasil, o impacto nos serviços de bares e restaurantes foi significativo, até agosto de 2020 "7\% dos bares e restaurantes fecharam devido à pandemia" (BOCCHINI, 2020). O volume de serviços no país teve uma queda de $9 \%$ de janeiro a agosto, e mais especificamente no Estado do Rio de Janeiro essa queda foi de $6,9 \%$ no mesmo período (IBGE, 2020). O Brasil, previamente à crise de COVID-19, já vinha se recuperando de uma crise econômica e, com essa nova recessão, dificultou o equilíbrio financeiro das organizações, principalmente as de serviços que demandam a presença do cliente, como os bares e restaurantes. As condições dessa situação acabam por forçar os bares e restaurantes, com intuito de se manterem no mercado, a tomar medidas de contenção de gastos, desligando contratos empregatícios e adotando atitudes econômicas, evitando-se despesas desnecessárias.

\subsubsection{Auxílio Governamental}

Diante da crise de COVID-19 e suas consequências econômicas para micro, pequenas e médias empresas, o Governo Federal optou por criar meios para auxiliá-las a superar o momento de recessão atual.

No mês de março de 2020 o Governo Federal anunciou o primeiro programa para auxiliar pequenas e médias empresas, com faturamento entre $\mathrm{R} \$ 360$ mil a $\mathrm{R} \$ 10$ milhões anuais, a quitar suas folhas de pagamento, disponibilizando linhas de crédito por meio dos bancos (OLIVEIRA e VERDÉLIO, 2020). Em julho de 2020, novamente, o Governo Federal criou uma nova linha de crédito destinada a pequenas e médias empresas, desta vez com faturamento anual de até $R \$ 300$ milhões, cujo programa leva o nome de Capital de Giro para Preservação de Empresas (GCPE), segundo o site de notícias do governo, Governo do Brasil (2020).

Desse modo, por meio das linhas de créditos proporcionadas pelo Governo, os efeitos financeiros negativos causados pela pandemia de COVID-19 podem ser minimizados, mas ainda serão atuantes. Isso gera mais tempo para essas empresas conseguirem se recuperar, à medida que haja a gradual 
diminuição das regras de distanciamento social, afetando diretamente o setor de bares e restaurantes.

\subsubsection{Plano de Retomada Econômica e Restrições}

No município do Rio de Janeiro foi criado um plano de reabertura econômica gradual de 6 fases à medida que o monitoramento de indicadores de saúde permitirem (Figura 1).

Figura 1: Resumo das atividades classificadas

\begin{tabular}{|c|c|c|c|c|c|c|c|c|c|}
\hline $\begin{array}{l}\text { Procipama } \\
-100= \\
\sqrt{0} \sqrt{0}\end{array}$ & \multicolumn{9}{|c|}{$\begin{array}{l}\text { ATIVIDADES ECONÔMICAS NA RETOMADA } \\
\text { RESUMO DAS ATIVIDADES CLASSIFICADAS }\end{array}$} \\
\hline & $\overline{\text { FASE } 1}$ & $\overline{\text { FASE } 2}$ & FASE 3A & FASE 3B & FASE 4 & FASE 5 & FASE 6A & FASE 6B & \\
\hline जि COMÉRCIO & ( & (v) & ( & ( & ( & ( & ( & ( $)$ & \\
\hline AMBULANTES EM LOGRADOUROS & 2 & 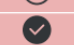 & 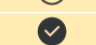 & 2 & 2 & 2 & 8 & 2 & \\
\hline 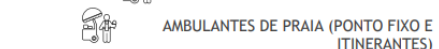 & O & O & O & 0 & 0 & $\Theta$ & ( & 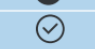 & \\
\hline (80) LANCHONETE, BAR E RESTAURANTE & $\Theta$ & ( & ( & ( & ( & ( & ( & ( & జี \\
\hline ACADEMIA & 0 & O & ( & 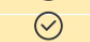 & ( & $\Theta$ & $\Theta$ & ( & 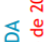 \\
\hline SERVICCOS & 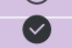 & $\vartheta$ & 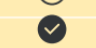 & 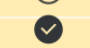 & 尺 & $\vartheta$ & 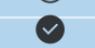 & 2 & 这 \\
\hline EDUCAC̄ÃO & O & O & O & O & ( & ( & ( & 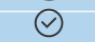 & 崖 \\
\hline 閿 TURISMO & ( ) & ( & 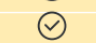 & 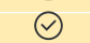 & 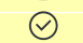 & $\Theta$ & ( & $\theta$ & 㟒 \\
\hline SALĀO DE BELEZA, TATUADOR E ESTETTICA & O & ( & ( & 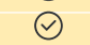 & 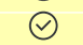 & 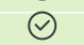 & ( & ( & 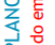 \\
\hline 鸟 AMBIENTES ABERTOS & 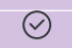 & 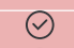 & ( & 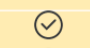 & $\ominus$ & $\ominus$ & 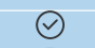 & ( & $\frac{\sqrt{3}}{\sqrt[3]{3}}$ \\
\hline SAUUDE & ( & ( & ( & $\Theta$ & ( ) & 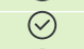 & ( & ( & \\
\hline (2) CULTURA & 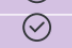 & ( & (৩) & $\Theta$ & $\Theta$ & $\Theta$ & 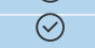 & ( & \\
\hline , LAZER E EVENTOS & 0 & 0 & 0 & $\bigcirc$ & $\bigcirc$ & ( & ( & ( & \\
\hline ESPORTE & $\ominus$ & ( & 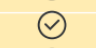 & $\ominus$ & ( & ( & ( ) & ( ) & \\
\hline CONSTRUCÁ̃ & 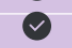 & 2 & 0 & & 0 & 0 & 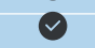 & 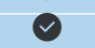 & \\
\hline
\end{tabular}

Fonte: Prefeitura da Cidade do Rio de Janeiro (2020)

Atualmente, o município se encontra na Fase 6B, em que lanchonetes, bares e restaurantes podem funcionar com restrições e seguindo as "regras de ouro" estabelecidas pela prefeitura (PIERRE, 2020). Segundo a Prefeitura da Cidade do Rio de Janeiro (2020), em fases anteriores, bares e restaurantes tinham restrições em relação ao horário de funcionamento, tendo sido na fase 3 até $23 \mathrm{~h}$, na fase 5 até as $1 \mathrm{~h}$ e atualmente está sem restrição. Além disso bares e restaurantes estavam operando com $50 \%$ de sua capacidade até a Fase $6 \mathrm{~A}$, porém atualmente o setor não pode ultrapassar de $2 / 3$ da capacidade total. Mesas devem respeitar um espaçamento de 2 metros entre si, é proibido o uso de pistas de danças e também do sistema self-service. 
Em relação às regras de ouro da prefeitura, as normas que devem ser seguidas a todo momento para evitar a propagação do vírus COVID-19 são as mostradas na Figura 2.

Figura 2: Regras de ouro da reabertura do Rio

\section{Regras de ouro da reabertura no Rio}

Prefeitura estabeleceu dez normas para todas as fases da retomada do comércio e dos serviço

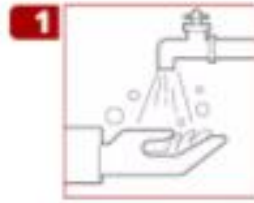

Higienizar as măos

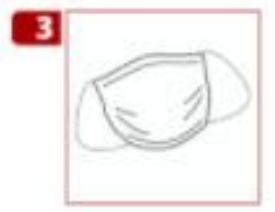

Usar máscara só retirar para comer

5

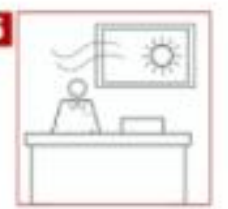

Manter ambientes arejados

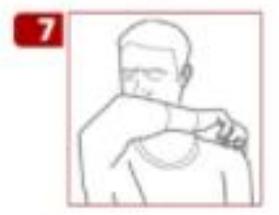

Cobrir o rosto ao tossir ou espirrar

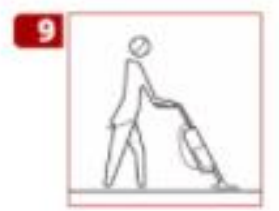

Fazer limpeza do ambiente a cada três horas

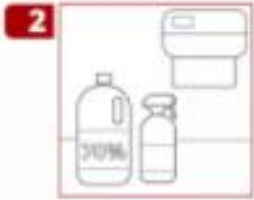

Disponibilizar âlcool 70\%, sabão líquido e papel-toalha

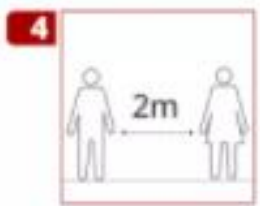

Manter dois $\mathrm{m}^{2}$ de distância

6

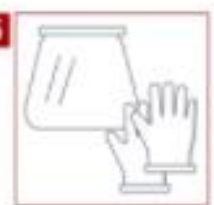

Providenciar EPIs para funcionários

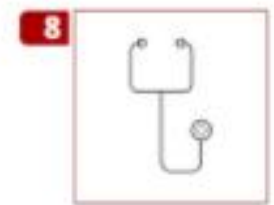

Encaminhar ao médico o funcionário com sintomas.

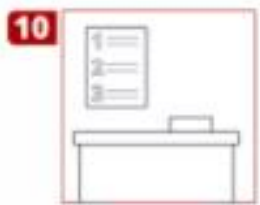

Divulgar medidas de prevenção

Fonte: G1 (2020) 
As restrições e regras de ouro da prefeitura são essenciais para manter a seguridade local e frear a disseminação do vírus. Os bares e restaurantes terão que se adequar a essas medidas para se manterem, e isso exige reorganização, planejamento e mais gastos para essas organizações, que dependerão de um bom gerenciamento para manter o negócio viável.

\subsubsection{Tendências Sustentáveis}

Tendências sustentáveis já é algo que vinha crescendo na sociedade brasileira. Segundo Nielsen (2019), aproximadamente $32 \%$ da população brasileira se preocupam com práticas e atitudes sustentáveis, inclusive no momento de decisão de compra de produtos e serviços. Além disso 95\% dos consumidores brasileiros acreditam que assuntos ambientais vão ganhar mais importância, 67\% procuram por produtos de empresas que tem preocupação com o meio ambiente e $65 \%$ procuram conhecer a origem do produto que compram (McKINSEY \& COMPANY, 2020). Observando esses dados, vemos que uma mentalidade sustentável já existe dentre os consumidores brasileiros, e já é algo levando em conta por algumas organizações.

Com a crise causada pela pandemia de COVID-19, algumas tendências sustentáveis foram aceleradas, podendo forçar as organizações a adotarem práticas sustentáveis mais rápido. Para o setor de bares e restaurantes as tendências mais relevantes são: o Manifesto Lixo-Zero, que compreende a ideia de produzir e consumir com geração zero de resíduos que são lançados na natureza e oceanos (SEBRAE/SC, 2020); e Flextarianos, "Nem veganos, nem vegetarianos. Este tipo de consumidor evita comer carne e prefere a alimentação vegetariana" (SEBRAE/SC, 2020, p.7). 


\section{Metodologia}

Este capítulo visa expor como a pesquisa foi realizada, levando em conta suas especificações técnicas. A seguir será abordado o tipo de pesquisa realizada, a seleção de sujeitos que foram entrevistados, o método usado para a coleta de dados, a técnica utilizada para o tratamento dos dados e as possíveis limitações do método utilizado.

\subsection{Tipo de pesquisa}

O seguinte trabalho foi realizado por meio de pesquisa de campo, sendo uma pesquisa do tipo descritivo. Os métodos descritivos "consistem em investigações de pesquisa empírica cuja principal finalidade é o delineamento ou análise das características de fatos ou fenômenos, a avaliação de programas, ou o isolamento de variáveis principais ou chave" (MARCONI e LAKATOS, 2003, p. 187). A pesquisa visa, especificamente, exibir a percepção dos donos de bares e restaurantes, descrevendo a opinião desse segmento, porém não necessariamente justificá-la.

\subsection{Seleção de sujeitos}

Foram contatados 10 indivíduos para participar da pesquisa por meio de ligação telefônica ou aplicativos de mensagem rápida. Destes dez, dois não responderam às perguntas, portanto foi um total de 8 indivíduos entrevistados. Todos os participantes são sócios ou sócias dos empreendimentos que representam, ou seja, possuem poder de decisão final apesar de o dividirem com os outros membros da sociedade. De qualquer modo se enquadram como donos ou donas dessas organizações na época das entrevistas (16 de novembro a 28 de novembro de 2020). 


\subsection{Coleta de dados}

Os dados desta pesquisa foram obtidos por meio de entrevistas em profundidade. As entrevistas possuíram um roteiro semiestruturado, de 9 perguntas, abrindo a possibilidade de rearranjo da ordem das perguntas e algumas adições específicas caso o entrevistador julgasse necessário. Além disso há algumas perguntas introdutórias com objetivo de identificar nome do entrevistado, do empreendimento, localização do empreendimento e porte do mesmo. Todas as entrevistas foram realizadas por meio da internet, com duração aproximada de 15 minutos. Nas figuras 3 e 4 abaixo, estão as perguntas feitas aos entrevistados.

Figura 3: Perguntas introdutórias.

Nome:

Idade:

Nível de Ensino:

( ) Ensino Fundamental Incompleto

( ) Ensino Fundamental Completo

( ) Ensino Médio Incompleto

( ) Ensino Médio Completo

( ) Ensino Superior Incompleto

( ) Ensino Superior Completo

Nome (fantasia) de seu empreendimento:

Bairro do empreendimento:

Qual o porte de seu empreendimento:

( ) Pequeno Porte - Faturamento anual maior que $\mathrm{R} \$ 360$ mil e menor ou igual que $\mathrm{R} \$ 4,8$ milhões.

( ) Médio Porte - Faturamento anual maior que $\mathrm{R} \$ 4,8$ milhões e maior ou igual a $\mathrm{R} \$ 300$ milhões.

( ) Grande Porte - Faturamento anual maior que $\mathrm{R} \$ 300$ milhões.

Fonte: Elaborado pelo autor. 
Figura 4: Perguntas feita aos entrevistados

1. Quais foram os maiores efeitos/consequências ocasionados pela pandemia de COVID-19 no seu setor de atuação e para o seu estabelecimento?3

2. Como seu empreendimento está lidando com esses efeitos ocasionados pela pandemia de COVID-19? Alguma estratégia em particular pode ser citada?

3. Qual a sua expectativa, em relação ao desempenho do seu empreendimento, no curto/médio prazo?

4. Quais mudanças significativas você entende que vieram pra ficar, devido à pandemia de COVID-19?

5. O que você entende como sustentabilidade? No seu setor ela é importante? Como?

6. No seu entendimento, em seu empreendimento, quais práticas sustentáveis são feitas (caso sejam)? E quais as consequências delas?

7. Você notou alguma tendência sustentável crescer, em seu empreendimento ou entre os concorrentes, durante a pandemia de COVID-19?

8. Qual o seu maior impedimento para implementar práticas sustentáveis?

9. Como você vê o tema sustentabilidade (em bares e restaurantes) em meio a essa crise pandêmica de COVID-19? E para o futuro, a sustentabilidade poderá gerar algum diferencial nesse setor?

Fonte: Elaborado pelo autor. 


\subsection{Tratamento dos dados}

A pesquisa utiliza uma abordagem qualitativa dos dados, que "permite abordar atitudes, valores, representações, mentalidades e ideologias" (LAVILLE e DIONNE, 1999, p. 214-215) e com isso indicar a percepção dos entrevistados sobre o tema proposto durante a crise de COVID-19. Para a avaliação dos dados foi utilizada análise de discurso, em que partes da fala dos entrevistados foram transcritas e comparadas, para se chegar a um resultado.

\subsection{Limitações do método}

Segundo Creswell (2007), as limitações visam expor os principais pontos fracos do método aplicado. No caso da entrevista em profundidade, pode haver a possibilidade do(a) entrevistado(a) não expressar sua real opinião por considerá-la "malvista". Há também chance de o(a) entrevistado(a) omitir informações por presumi-las que sejam fraquezas de seu empreendimento e entender ser desvantajoso compartilhá-las. Além disso o(a) entrevistado(a) pode mentir a respeito de algum elemento para passar uma boa imagem de seu empreendimento. As limitações, caso ocorram, interferem na precisão do resultado final da pesquisa, podendo gerar conclusões distantes da realidade. 


\section{Análise de Resultados}

Neste capítulo será apresentado os resultados obtidos através da análise do conteúdo gerado pelas entrevistas. Inicialmente será apresentado um breve resumo sobre o perfil dos entrevistados e dos empreendimentos e em seguida 0 resultado da análise da pesquisa qualitativa.

\subsection{Perfil dos Entrevistados e Empreendimentos}

Os entrevistados(as) têm uma média de idade de 56 anos, $62,5 \%$ são do sexo masculino e $37,5 \%$ feminino. Todos os participantes possuem um alto nível de ensino, possuindo ensino superior completo. A fim de resguardar os nomes dos entrevistados, estes serão representados apenas por letras e não pelos seus nomes inteiros. Na Tabela 1, estão o perfil de cada um dos entrevistados.

Tabela 1: Perfil dos Entrevistados.

\begin{tabular}{|l|l|l|l|}
\hline Nome & Sexo & Idade & Nível de Ensino \\
\hline N.A. & Feminino & 54 & Superior Completo \\
\hline C.P. & Feminino & 57 & Superior Completo \\
\hline H.L. & Feminino & 42 & Superior Completo \\
\hline O.B. & Masculino & 58 & Superior Completo \\
\hline N.B. & Masculino & 59 & Superior Completo \\
\hline R.C. & Masculino & 55 & Superior Completo \\
\hline H.K. & Masculino & 60 & Superior Completo \\
\hline A.C. & Masculino & 66 & Superior Completo \\
\hline
\end{tabular}

Fonte: Elaborado pelo autor.

Em relação aos empreendimentos, cinco (62,5\%) estão localizados na zona oeste e três na zona central do município. Dos oito restaurantes, 7 são de pequeno porte e apenas um é médio porte, ou seja, a maioria possui um faturamento anual menor que $\mathrm{R} \$ 4,8$ milhões. Abaixo na Tabela 2, está o perfil de cada um dos empreendimentos. 
Tabela 2: Perfil dos empreendimentos.

\begin{tabular}{|l|l|l|l|}
\hline Entrevistado(a) & \multicolumn{1}{|c|}{ Empreendimento } & \multicolumn{1}{|c|}{ Bairro } & Porte \\
\hline N.A. & DC Grill Churrascaria Ltda & Centro & Pequeno \\
\hline C.P. & La Nonna Galeteria & Barra da Tijuca & Pequeno \\
\hline H.L. & Temkilo & Jacarépaguá & Pequeno \\
\hline O.B. & Beco do Alemão & Barra da Tijuca & Médio \\
\hline N.B. & Saara Grill & Centro & Pequeno \\
\hline R.C. & Ulisses Restaurante & Cidade Nova & Pequeno \\
\hline H.K. & Becco Restaurante & Barra da Tijuca & Pequeno \\
\hline A.C. & Becco Pontal Restaurante & $\begin{array}{l}\text { Recreio } \\
\text { Bandeirantes }\end{array}$ & Pequeno \\
\hline
\end{tabular}

Fonte: Elaborado pelo autor.

\subsection{Entrevistas}

As entrevistas realizadas com esses participantes tiveram como objetivo identificar a percepção sobre sustentabilidade durante a pandemia de Covid-19 através da análise de discurso.

Uma observação importante é que houve diferenças nas respostas dos entrevistados no quesito de objetividade, enquanto uns discursavam mais e transmitiam muitos detalhes outros foram muito objetivos e com menos detalhes. Isso pode ser atribuído ao fato de que mesmo o indivíduo sendo sócio do empreendimento, isso não significa que o mesmo atue integralmente na empresa, apenas visitando a organização quando necessário. Essa característica não invalida a percepção do indivíduo, pois de qualquer modo, este ainda tem poder de decisão final sob o empreendimento, porém mostra um desconhecimento dos afazeres diários que pode dificultá-lo a saber de práticas sustentáveis realizadas, tendências ou problemas que ocorram em sua organização.

Inicialmente quando perguntados sobre as consequências da pandemia sob seus empreendimentos, todos os entrevistados deram respostas similares. Muitos enfatizaram a queda drástica de faturamento e o fechamento temporário 
das organizações, vistas como eventos abruptos que ocorreram rapidamente e praticamente sem aviso prévio.

"O maior efeito foi a interrupção repentina da nossa receita, de um dia pro outro perdemos $100 \%$ da receita..." (H.K.).

"O maior efeito da consequência da covid no negócio foi uma queda brutal de faturamento chegando a ser, quer dizer, o faturamento estar em $10 \%$ do que era, realmente é desesperador" (A.C.).

"Foi terrível, o nosso capital de giro foi embora em um mês e pouco, então foi uma situação ruim, ficamos devendo fornecedores, ficamos devendo impostos, então foi terrível..." (O.B.).

Todos alegaram ter fechado seus empreendimentos, ficando de 2 a 4 meses fechados. Os empreendimentos localizados na zona central da cidade foram mais afetados nesse sentido, ficando por 4 meses fechado. Como aponta R.C.:

\footnotetext{
Bom, como nosso negócio, ele depende, ele é um restaurante que depende exclusivamente das empresas onde ele fica situado para funcionar, porque ele trabalha exclusivamente com almoço executivo. Ele é, foi muito afetado com a pandemia porque as empresas deixaram de ter o trabalho onsite, ou seja, elas deixaram de frequentar o escritório por conta da pandemia e passaram a fazer o trabalho home office e com isso a gente ficou sem público. Então todo esse setor de restaurante que trabalha com almoço executivo foi muito afetado e o nosso não é diferente disso. (R.C.).
}

Devido ao home office adotado pelas empresas no entorno e ter poucas moradias residenciais próximas, os estabelecimentos na zona central não tiveram a opção de mudar para a modalidade de delivery, sendo mais prejudicados que os restaurantes da zona oeste por exemplo.

Em seguida os participantes foram perguntados sobre suas estratégias para lidar com a situação atual. As respostas foram levemente variadas, mas essencialmente muita das estratégias foram similares para todos os empreendimentos. A recorrência ao uso dos auxílios e programas criados pelo 
governo federal foi muito citado, não só as linhas de crédito para empréstimos, mas também o programa de suspensão de contrato de funcionário. O delivery foi o mais mencionado como uma estratégia de solução pelos participantes, porém destacaram que houve uma demora para se adequar a essa nova modalidade.

A terceira pergunta feita se referiu a expectativa de curto/médio prazo dos entrevistados em relação aos seus empreendimentos. Nessa questão N.A., H.K. e A.C. disseram que suas expectativas são ruins a curto/médio prazo, principalmente pelo menor movimento de clientes. N.A. comenta que ao reabrirem, o movimento caiu em $85 \%$ e a mesma tendência ocorreu nos estabelecimentos dos outros participantes, em diferentes graus.

A expectativa não é boa. A curto e médio prazo não tem nenhuma
expectativa de melhora... O nosso movimento de clientes hoje não
passa de $50 \%$, então é impossível você conseguir tocar um
empreendimento com metade da sua receita. (H.K.).

H.L. destaca que com uma possível vacina sendo produzida e distribuída em janeiro ou fevereiro, a participante espera que sua clientela volte a $80 \%$ ou $90 \%$ do que era antes da pandemia. Já A.C. diz que mesmo com o início da distribuição da vacina ainda demorará um pouco para todos os clientes voltarem. De modo geral, a maioria dos participantes não possuem uma visão otimista a curto/médio prazo. Pelos estabelecimentos serem, em sua maioria, espaços fechados, grande parte dos clientes vão evitar frequentá-los, dando preferência para locais abertos e que sigam as regras de higiene. A participante C.P., a única que possui uma visão otimista, afirma:

"A gente tem uma varanda onde as mesas ficam espaçosas ao ar livre, as pessoas começaram a ter mais confiança e coragem, nosso movimento começou a melhorar a partir de julho...” (C.P.).

A expectativa é boa porque a gente já tá nesse momento com
atendimento de almoço e jantar, claro, com horário reduzido. Ainda
assim todos os funcionários, praticamente todos os funcionários
voltaram ao trabalho, agora em novembro. E a gente, realmente, está
bem confiante, porque como a gente tomou todas as precauções em
relação a higiene e manipulação de alimentos, as pessoas estão
também se protegendo com máscaras. Como o nosso sistema é
rodízio não precisa o uso de nenhum tipo de luva, a comida é toda 
levada a mesa do cliente, então o cliente não precisa circular, ele chega, senta e é atendido. E nós estamos confiantes porque estamos fazendo tudo direitinho e tá tendo retorno, isso é uma conclusão positiva. (C.P.).

Em relação as mudanças que vieram para ficar, causadas pela pandemia, duas respostas foram as mais comuns. A primeira é a adoção do delivery, como já citado antes, esse foi o método mais utilizado pelos participantes para superar a crise causada pela pandemia de COVID-19. Grande parte dos entrevistados não tinham esse tipo de serviço, portanto acreditam que isso possa se tornar algo permanente em sua operação.

\footnotetext{
...o delivery foi um serviço que não tínhamos, que tivemos que começar a trabalhar e vai ficar né, pra sempre. Não tem como mudar, porque com essas questões das restrições o cliente acaba ficando mais isolado em casa, não saindo... (H.L.).
}

A segunda é a adoção de home office das empresas. As empresas que possuem escritórios estão percebendo que há um ganho de produção com essa adoção e existe uma grande possibilidade do uso permanente dessa prática. Caso isso ocorra, irá afetar fortemente os empreendimentos da zona central da cidade, cujos principais clientes são funcionários desse tipo de empresa.

\footnotetext{
No nosso caso particular, a mudança que veio pra ficar é que muito do contingente das empresas não vai voltar ao escritório. As empresas grandes com, sei lá, mais de mil funcionários como é o caso da nossa, que a gente atendia, até a prefeitura, conversando com as pessoas que foram lá (ao restaurante), que trocaram essas experiências comigo, eles perceberam que existe um ganho de produtividade no fato da pessoa poder trabalhar no home office. (R.C.).
}

C.P. e H.L. apontam que a partir de agora haverá uma preocupação muito maior com higiene e limpeza dos espaços e equipamentos e haverá maior cobrança e capricho do funcionário. Além disso R.C. e C.P. destacam que perceberam que possuíam mais empregados que o necessário, e com a crise pandêmica notaram que conseguem operar com menos pessoas.

Um destaque relevante é que até esse ponto da entrevista (pergunta 4 do questionário) nada sobre o tema de sustentabilidade foi citado nas perguntas e nem nas respostas. Isso não é um indicativo de que os participantes não deem 
relevância ao tema, porém pode demonstrar que nesse setor (de bares e restaurantes), este não é um assunto muito recorrente no dia a dia dos empreendimentos. Ainda mais levando em conta a pandemia de COVID-19, que naturalmente redireciona o foco dos participantes para a sobrevivência do negócio.

O entendimento de sustentabilidade dos participantes foi, de modo geral, similar. Na maioria das respostas, o aspecto ambiental de sustentabilidade foi 0 mais referido. H.L., H.K. e R.C. abordaram o tema de forma mais ampla, levantando o aspecto econômico e social, quando definiram o termo sustentabilidade. Quase todos os participantes citaram como sustentabilidade a separação do lixo orgânico do reciclável, a economia de energia elétrica e água, o descarte adequado do óleo de cozinha e evitar o desperdício de alimentos. Essas práticas de fato são atreladas a uma gestão sustentável, mas não se trata apenas disso. O entrevistado N.B. comenta que:

\footnotetext{
Entendo que sustentabilidade são tomadas de decisão baseadas nos setores de alimentação para que a gente consiga trabalhar com produtos de sustentabilidade. Isso envolve organização dentro da churrascaria, parte da reciclagem de produto para que não contamine o meio ambiente, isso parte de você montar seu buffet com uma alimentação mais saudável, que o seu cliente chegue na tua casa, se sinta bem, coma e se sinta bem, não saia de lá com mal estar, de barriga cheia ou estufada, tem que ter uma alimentação balanceada, bem organizada para que a gente possa dar sequência no trabalho. (N.B.)
}

O entrevistado, assim como a maioria, atrela o termo sustentabilidade ao seu aspecto ambiental quando comenta sobre a reciclagem de produtos. Porém no entendimento do mesmo, sustentabilidade está ligada a alimentação saudável e balanceada do cliente, o que na realidade não está relacionado diretamente com uma gestão sustentável. N.B. ainda afirma que as práticas sustentáveis realizadas em seu estabelecimento, segundo seu entendimento, é a reciclagem dos materiais e estar de acordo com os padrões de higiene da ANVISA. Essas práticas de fato são sustentáveis, seguir os regulamentos de instituições sanitárias é uma obrigatoriedade e também indicativo de segurança para o cliente e, portanto, está inserido em um aspecto social do gerenciamento sustentável, porém o entrevistado não relata isso diretamente, demonstrando uma compreensão incompleta sobre o tema. 
H.L. e R.C. demonstraram ter entendimento mais amplo sobre o assunto, abordando em suas respectivas definições os aspectos social e econômico, além do ambiental, o que vai ao encontro com a definição do triple bottom line.

Sustentabilidade, eu entendo como a sobrevivência dos recursos naturais tanto para os empreendimentos quanto para a sociedade. Isso é construído em três pilares para mim, o econômico, o social e o ambiental. Eu acho importante sim, como utilizar práticas diárias no estabelecimento em relação a questão social, econômica e ambiental... (H.L.).

Quando perguntado sobre as práticas realizadas em seu empreendimento, R.C. responde:

Sustentabilidade no meu ramo de restaurante é você buscar sempre qualidade usando o mínimo de recursos, procurar usar produtos de boa qualidade, cada vez de melhor qualidade com procedência. Cada vez mais o mercado busca isso, entender da onde está vindo o produto, como ele é produzido, se é produzido de forma sustentável, se ele está degradando de alguma forma o meio ambiente, a procedência é fundamental, se tem todos os registros de verificação sanitária etc. E você tentar buscar cada vez mais otimizar os recursos que você tem a mão. Fazer a coisa da melhor maneira, da maneira mais otimizada possível. No nosso caso lá, a gente reciclava produtos, latas de alumínios, a gente separava e depois trocava por sabão ou pano de chão, o óleo usado também. Então esses pequenos atos fazem você otimizar o máximo que você tem na mão. $E$ também com relação aos próprios funcionários, você dar o máximo de condições pra ele ter um ambiente de trabalho saudável... (R.C.)

O entrevistado aborda, simplificadamente, todos os aspectos da sustentabilidade, de acordo com a definição do triple bottom line. Saber a procedência do produto, ser mais eficiente na operação e no uso de recursos, reciclar produtos, e dar as condições para os funcionários ter um bom ambiente de trabalho entram em concordância com uma perspectiva ampla de uma gestão sustentável.

No caso de H.K., quando o entrevistado define o termo sustentabilidade ele se refere ao âmbito econômico, social e ambiental. 


\begin{abstract}
O que eu entendo que uma atividade é sustentável, é quando ela consegue ser desenvolvida respeitando a natureza, trazendo benefícios para a coletividade, para a sociedade e ao mesmo tempo traz resultados financeiros para o investidor (H.K.).
\end{abstract}

Porém, quando perguntado sobre as práticas sustentáveis realizadas em seu estabelecimento, H.K. apenas destaca atividades ligadas ao aspecto ambiental como economia de água, energia elétrica, destino adequado a resíduos etc. Isso evidencia que apesar de entender o tema sustentabilidade de modo geral, pode haver um desconhecimento em como os outros aspectos se expressam na prática no setor de bares e restaurantes.

No tocante às possíveis novas tendências sustentáveis durante a pandemia, as respostas foram bem variadas. C.P. afirma ter notado um aumento de ofertas de empresas de coleta de lixo reciclado e óleo usado e acredita que o "mercado de lixo" está crescendo. H.L. afirma que notou um aumento da conscientização sobre sustentabilidade, de modo geral. O.B. e N.B. destacam que o delivery foi uma tendência sustentável que surgiu na pandemia e H.K. e A.C. declaram que não perceberam nenhuma tendência sustentável, H.K. ainda diz que na realidade a pandemia foi negativa para uma gestão sustentável devido ao aumento do uso de materiais descartáveis nos bares e restaurantes.

"As mudanças de habito decorrente da covid-19 não contribuem para as práticas sustentáveis, tanto que temos muitos clientes que preferem copos descartáveis em vez de copo de vidro e trocamos os panos de mesa pôr panos descartáveis" (H.K.).

A tendência de uso do delivery de fato vai ao encontro dos aspectos social e financeiro da gestão sustentável, pois além de ser uma saída à crise econômica também significa responsabilidade social, pois evita as pessoas irem presencialmente ao restaurante. Apesar de também ser considerado uma responsabilidade social, é entendido que a motivação principal para o uso do delivery é financeira focando a sobrevivência do negócio em meio a crise. Em relação a afirmação de H.K. em que a pandemia foi negativa as práticas sustentáveis, reforça um maior entendimento atrelado ao aspecto ambiental da sustentabilidade. 
Em relação ao maior impedimento para implementação de práticas sustentáveis, a maioria dos participantes indicaram ser o alto custo, principalmente em meio a pandemia. Os equipamentos, produtos ou até sistemas mais adequados e sustentáveis, normalmente possuem um preço alto, significando um investimento considerável, algo que no momento atual é inviável. As respostas dos participantes nesse quesito foram mais direcionadas ao aspecto ambiental e consequentemente econômico também, citando produtos ou equipamentos sustentáveis que sejam menos nocivos ao meio ambiente e gerem economia, como por exemplo no uso de placas solares para geração de energia própria e sistemas de captação de chuva.

No que se refere a como o entrevistado vê o tema sustentabilidade em meio a pandemia e a importância da mesma para o futuro no setor de bares e restaurante, C.P. e R.C. relatam, de maneiras diferentes, que houve aumento de conscientização do uso de recursos devido a situação crítica (causada pela crise), obrigando o estabelecimento a ser o mais eficiente possível para sobreviver. C.P., H.L., N.B., N.A. e R.C. declaram que a sustentabilidade é muito importante para o futuro do setor. Já H.K. reafirma que a pandemia foi negativa para práticas sustentáveis e A.C. comenta que durante a pandemia a sustentabilidade ficou em segundo plano. 


\section{Conclusão}

O objetivo proposto por este trabalho é entender a percepção do tema sustentabilidade durante a crise pandêmica de COVID-19 sob o olhar de donos de bares e restaurantes. A sustentabilidade é um assunto importante e atual e mesmo que não haja uma compreensão total sobre, muito provavelmente as pessoas realizam uma ou outra prática sustentável, sem saber. Dependendo da perspectiva do indivíduo, sustentabilidade pode ser expressa de diversas maneiras e atividades ou simplesmente ser atrelada a uma só compreensão ou conjunto de ações.

Quando se trata de exemplificar atividades sustentáveis e classifica-las pode haver uma dificuldade, dependendo da percepção que se tem sobre o assunto. No setor de bares e restaurantes, uma gestão sustentável abrange três aspectos, o econômico, o social, e o ambiental. O principal objetivo de se adotar uma gestão desse tipo é equilibrar esses três grupos, de modo que o estabelecimento evite danos ao meio ambiente, seja diretamente ou indiretamente, respeite a sociedade, seja entre seus funcionários ou entre a população que vive no entorno, no bairro, e consiga gerar lucro ou ao menos sobreviver.

Cada atividade sustentável pode ter um resultado atrelado a um ou mais dos três aspectos da sustentabilidade. Um sistema de captação de chuva e a instalação de placas fotovoltaicas geram economia financeira, pois diminuirá o gasto com água e energia elétrica respectivamente, por outro lado, dependendo de como for a geração de energia elétrica municipal utilizada pelo estabelecimento, limpa ou poluidora, o uso da placa pode estar contribuindo para um método menos nocivo ao meio ambiente. Neste caso, uma atividade esta atrelada ao aspecto econômico e ambiental.

Em bares e restaurantes existem diversos modos de fazer uma gestão sustentável e equilibrar os três aspectos. Métodos para evitar desperdício de alimentos, como montar um cardápio, um buffet ou um prato com o mínimo necessário; instalação de sistema de captação de chuva; uso eficiente de água e energia, evitando usa-los desnecessariamente; treinamento e conscientização dos colaboradores, para que estes realizem seus afazeres de modo adequado e 
evitando desperdícios; instalação de equipamentos econômicos, que utilizem energia e água da forma mais eficiente possível; ter uma boa gestão de resíduos, contratando empresas de coleta de lixo reciclável e óleo de cozinha cadastradas em programas do governo municipal como o PROVE (Programas de Reaproveitamento de Óleos Vegetais) e que sigam as regras vigentes pelas instituições de higiene e ambiental; ter uma gestão de cadeia de suprimentos sustentável, comprando produtos de organizações que sigam as leis vigentes e que tenham um gerenciamento sustentável, e também cobrando-as caso não tenham; ter uma boa responsabilidade social empresarial, incluindo tanto seus colaboradores como a população local, concedendo um ambiente de trabalho adequado, seguindo as leis trabalhistas, contribuindo com a sociedade local, realizando possíveis eventos para a comunidade, valorizando a cultura local, participando de possíveis programas como o caso da ONG espanhola Ação contra Fome, e seguindo as regras de higiene de instituições governamentais.

Com a crise causada pela pandemia de COVID-19, o setor de bares e restaurantes foi um dos mais afetados, principalmente por demandar presença dos clientes para que funcione. No Rio de Janeiro, os restaurantes ficaram fechados de 2 a 4 meses, sem nenhuma opção de funcionamento, devido a quarentena imposta pelo governo estadual. Nesse meio tempo, programas de linha de créditos oferecidos pelo governo federal foram essenciais para manterem os empreendimentos do setor sobrevivendo enquanto não podiam funcionar. Na reabertura dos restaurantes, muitos tiveram que seguir as regras de ouro da prefeitura do Rio de Janeiro e obedecer às restrições impostas, como atender apenas $50 \%$ de sua capacidade, mesas devem estar com pelo menos 2 metros de distância entre si, o uso de máscara obrigatório etc. Com essas restrições, vários empreendimentos tiveram uma queda drástica do movimento de clientes, alguns casos caindo até $85 \%$, devido as regras de isolamento social impostas pelo governo estadual. A solução para a maioria dos bares e restaurantes foram começar a fazer entregas online, se cadastrando em aplicativos de delivery para terem alguma fonte de receita. Houve grande esforço para otimizar as operações, evitando ao máximo desperdícios (tanto de alimento, quanto água e energia), e com isso notou-se que a quantidade de colaboradores empregados era maior que necessário, possivelmente causando os estabelecimentos a reestruturarem seu quadro de funcionários. Alguns restaurantes da zona central do Rio de Janeiro, acabaram ficando mais prejudicados pois grande parte dos escritórios no qual atendem, começaram a adotar o home office, e perceberam, em sua maioria, que há um ganho de 
produtividade com esse método. Pelo fato de a zona central ter poucas moradias residenciais, o delivery acabou não sendo uma opção viável, obrigando os estabelecimentos permanecerem fechados por mais e dependerem mais dos auxílios governamentais.

A percepção sobre o tema sustentabilidade dos donos de bares e restaurantes, na maioria das respostas, foram muito atreladas ao aspecto ambiental. Há dois participantes que possuem um entendimento mais amplo do tema, abordando os outros dois aspectos, mas nesse caso, representam a minoria dos entrevistados. Quando foi abordado a sustentabilidade de modo mais específico, solicitando ações sustentáveis práticas, ficou evidente que a maioria atrela o assunto ao aspecto ambiental, alimentação saudável e higiene. A higiene que, é algo atrelado a responsabilidade social, principalmente devido a pandemia, apesar de citada parece não haver o entendimento de que pertence ao aspecto social na sustentabilidade. O aspecto econômico é naturalmente reconhecido pelos participantes, logicamente, independente de praticar uma gestão sustentável, essa dimensão é o foco principal de um estabelecimento para se manter em funcionamento e gerar lucro.

O conhecimento dos participantes sobre o aspecto ambiental da sustentabilidade, no entanto, pareceu ser completo. Muitas práticas dessa dimensão são mais reconhecidas não só pelo tema ambiental estar em alta atualmente, devido as mudanças climáticas, mas também por sabidamente oferecerem um retorno econômico. Esse é o caso de equipamentos industriais de cozinha que sejam mais econômicos e eficientes, como também os sistemas de captação de chuva, de reutilização de água, a separação dos lixos, a coleta de óleo, e a implementação de placas solares.

O aspecto social foi o menos reconhecido e citado, e quando foi abordado ações práticas, a minoria chegou a abordar elementos dessa dimensão. Acredito que não haja um reconhecimento preciso sobre responsabilidade social externa por parte dos participantes. A responsabilidade social interna, que representa todos os direitos e deveres para com os funcionários é, logicamente, mais citado e identificado pelos entrevistados. É importante ressaltar que mesmo que os estabelecimentos pertencentes aos entrevistados realizem alguma atividade do aspecto social, grande parte dos participantes não demonstraram ter conhecimento que tal atividade pertence a essa dimensão.

Em relação a percepção do tema sustentabilidade no setor durante a COVID-19, os participantes relacionaram o tema com atividades de economia de 
consumo de recursos, principalmente focado em evitar desperdícios e diminuição de gastos. Nessa questão, houve uma maior percepção sobre gastos desnecessários que ocorriam, e a sensibilidade dos donos de bares e restaurantes em relação a isso ficou maior, principalmente porque o ambiente externo se tornou hostil (no sentido econômico). Outros participantes alegaram que, sustentabilidade acabou ficando em segundo plano ou foi negativamente afetada pela pandemia de COVID-19, dando exemplos de consequências no âmbito ambiental.

Desse modo, a percepção sobre sustentabilidade na pandemia de donos de bares e restaurantes foi muito relacionado ao âmbito ambiental. Não houve uma mudança significativa, ocasionado pela pandemia, da percepção sobre o tema. Porém entendeu-se que ocorreu uma maior preocupação com otimização de operação, desperdício de recursos e aspectos de higiene, o que de certo modo, contribuem para uma direção a um gerenciamento sustentável. Essas novas práticas foram, obviamente, provocadas por necessidade e obrigações impostas pelas instituições governamentais. Portanto, de modo generalizado, os donos de bares e restaurantes possuem uma percepção sobre sustentabilidade durante a pandemia, muito ligada a questão ambiental e econômica, e com um baixo entendimento sobre o âmbito social, não só em sua definição mas também no que se refere a como isso se expressa na prática.

Apesar de ter uma gestão sustentável completa não ser uma obrigatoriedade e nem uma necessidade atualmente para os estabelecimentos de bares e restaurantes, a tendência é que a preocupação com esse tema cresça nos próximos anos. Ter um entendimento maior sobre o assunto, sobre sua importância e praticá-la pode ser um diferencial para uma organização no mercado, e pode garantir a sobrevivência do negócio a longo prazo. 


\section{Referências Bibliográficas}

ABIA. 12 Congresso Internacional de Food Service. 2019. Disponível em: https://www.abia.org.br/cfs2019/mercado.html. Acesso em: 23 de set, 2020.

ABRASEL. Como posso implementar processos de responsabilidade empresarial no meu estabelecimento?. 2019. Disponível em: $<$ https://abrasel.com.br/conexao/cursos/como-posso-implementar-processos-deresponsabilidade-empresarial-no-meu-estabelecimento $>$. Acesso em 24 de out, 2020.

ACCIÓN CONTRA EL HAMBRE. 2020. Disponível em: $<$ https://www.accioncontraelhambre.org/es>. Acesso em 24 de outubro, 2020.

ALVARENGA, D. Tombo recorde do PIB: veja setores mais e menos afetados na pandemia. G1, Brasil, 1 set. 2020. Disponível em: <https://g1.globo.com/economia/noticia/2020/09/01/tombo-recorde-do-pib-vejasetores-mais-e-menos-afetados-na-pandemia.ghtml> Acesso em 12 de outubro, 2020.

BARTIK, A. W.; BERTRAND, M.; CULLEN, Z. B.; GLAESER, E. L.; LUCA, M.; STANTON, C. T. How are small businesses adjusting to COVID-19? Early evidence from a survey (No. w26989). National Bureau of Economic Research, 2020.

BESKE, P. Dynamic capabilities and sustainable supply chain management. International Journal of Physical Distribution \& Logistics Management, v.42, n.4, p.372-387, 2012.

BNDES. Porte de Empresa. BNDES, 2018. Disponível em: $<$ https://www.bndes.gov.br/wps/portal/site/home/financiamento/guia/porte-deempresa>. Acesso em: 23 de set, 2020. 
BOCCHINI, B. $7 \%$ dos bares fecharam devido a pandemia. Agência Brasil, São Paulo, 28 ago. 2020. Disponível em: <https://agenciabrasil.ebc.com.br/economia/noticia/2020-08/sebrae-7-dos-barese-restaurantes-fecharam-devido-pandemia>. Acesso em 26 de out, 2020.

BOOF, L. Sustentabilidade: O que é - O que não é. Petrópolis, RJ: Vozes, 2017.

CRESWELL, J. W. Qualitative inquiry and research design: Choosing among five approaches. California: Sage, 2007.

DOS SANTOS, R. A. Mercado de Alimentação fora do Lar. SEBRAE, Acre, 2017. Disponível em $<$ https://www.sebrae.com.br/sites/PortalSebrae/ufs/ac/artigos/alimentacao-forado-

lar,19cfb3656dc20610VgnVCM1000004c00210aRCRD\#: :text=Conforme\%20da dos\%20do\%20IBGE\%20(2015,\%2C7\%25\%20do\%20PIB\%20brasileiro> Acesso em: 23 de set, 2020.

DOS SANTOS, R. Os desafios da Responsabilidade Social Empresarial na relação com o Empowerment Comunitário: Um estudo de caso da Favela do Jardim Colombo, na cidade de São Paulo. Campinas, 2008. 150 p. Dissertação (Mestrado em Educação) - Universidade Estadual de Campinas.

GANDRA, A. Rio lança cartilha para funcionamento de bares e restaurantes: Retomada das atividades está prevista para 2 de julho. Agência Brasil, Rio de Janeiro, 7 de jun, 2020. Disponível em: <https://agenciabrasil.ebc.com.br/saude/noticia/2020-06/rio-lan\%C3\%A7acartilha-para-funcionamento-de-bares-e-restaurantes> Acesso em: 23 de set, 2020.

GOSSLING, S.; SCOTT, D.; \& HALL, C. M. Pandemics, tourism and global change: A rapid assessment of COVID-19. Journal of Sustainable Tourism, v. 29 , n. 1, p. 1-20, 2020.

Governo do Brasil. Governo cria novo programa de apoio às micro, pequenas e médias empresas. 2020. Disponível em: <https://www.gov.br/ptbr/noticias/financas-impostos-e-gestao-publica/2020/07/governo-cria-novo- 
programa-de-apoio-as-micro-pequenas-e-medias-empresas> Acesso em: 28 de outubro, 2020.

GREEN RESTAURANT ASSOCIATION. Green Restaurant ${ }^{\circledR}$ Certification Standards. 2018. Disponível em: <https://d3656a02-c3a1-4531-9b807bd14919d48c.filesusr.com/ugd/4d780f 5a38ce19ffc247d3a0b845f44fe894dd.pd f.> Acesso em: 22 de outubro, 2020.

Instituto Brasileiro de Geografia e Estatística. Pesquisa Mensal de Serviços. $2020 . \quad$ Disponível em: $<$ https://www.ibge.gov.br/estatisticas/economicas/servicos/9229-pesquisamensal-de-servicos.html?=\&t=resultados $>$

JOHNSON, J. G. B.; FAGGI, A.; VOIGT, A.; SCHNELLINGER, J.; BREUSTE, J. Environmental Perception among Residents of a Polluted Watershed in Buenos Aires. Journal of Urban Planning and Development., v. 141, n. 3, p. 250, 2015.

KOTLER, P. Administração de Marketing. São Paulo: Prentice Hall, 2000

LAVILLE, C.; DIONNE, J. A construção do saber: manual de metodologia da pesquisa em Ciências Humanas. Porto Alegre: Editora UFMG, 1999.

MARCONI, M. A.; LAKATOS, E. A. Fundamentos da Metodologia Científica. São Paulo: Editora Atlas S.A., 2003.

MCKINSEY \& COMPANY. Brazil 2020 Opportunity Tree. São Paulo, 2020. Disponível em: <https://www.mckinsey.com.br/ /media/McKinsey/Locations/South\%20America/B razil/Our\%20Insights/Brazil\%202020\%200pportunity\%20Tree/McKinsey20200p portunityTree.ashx> Acesso em: 29 de outubro, 2020.

MORETTI, G. N.; SAUTTER, K. D.; AZEVEDO, J. A. M. ISO 14001: implementar ou não? Uma proposta para a tomada de decisão. Revista Engenharia Sanitária, v. 13, n. 4, p. 416-425, 2008. 
NIELSEN. Produtos Sustentáveis de Higiene \& Beleza Crescem em Consumo e Aumentam Participação no Faturamento da Indústria. 8 out, 2019.

Disponível em:

$<$ https://www.nielsen.com/br/pt/insights/article/2019/produtos-sustentaveis-dehigiene-beleza-crescem-em-consumo-e-aumentam-participacao-no-faturamentoda-industria/> Acesso em: 29 de outubro, 2020.

OLIVEIRA, K.; VERDÉLIO, A. Conheça detalhes do auxílio a pequenas e médias empresas. Agência Brasil, Brasília, 27 mar. 2020. Disponível em: $<$ https://agenciabrasil.ebc.com.br/economia/noticia/2020-03/conheca-detalhesdo-auxilio-a-pequenas-e-medias-

empresas\#: :text=0\%20governo\%20anunciou\%20hoje\%20(27,quitar\%20a\%20f olha\%20de\%20pagamentos.\&text=0\%20cr\%C3\%A9dito\%20ser\%C3\%A1\%20de stinado\%20a,R\%24\%2020\%20bilh\%C3\%B5es\%20por\%20m\%C3\%AAs.> Acesso em: 28 de outubro, 2020.

PIERRE, E. Prefeitura do Rio diz que bares e restaurantes podem funcionar sem horário para fechar. G1, Rio de Janeiro, 20 out. 2020. Disponível em: <https://g1.globo.com/ri/rio-de-janeiro/noticia/2020/10/20/prefeitura-do-rio-dizque-bares-e-restaurantes-podem-funcionar-sem-horario-para-fechar.ghtml> Acesso em: 28 de outubro, 2020.

PORTER, M.; KRAMER, M. Strategy and Society: The Link Between Competitive Advantage and Corporate Social Responsibility. HBR Spotlight, Harvard Business Review. Dezembro, 2006.

Prefeitura da Cidade do Rio de Janeiro. Plano de Retomada da Cidade do Rio de Janeiro em Função dos Impactos da Pandemia da COVID-19. Rio de Janeiro, 19 out, 2020. Disponível em: <https://riocontraocorona.rio/plano-deretomada/\#: :text=Plano\%20de\%20Retomada\%20Fase\%206B,do\%20dia\%2002 \%2F06)> Acesso em: 28 de outubro, 2020.

SANTOS, L. P. A.; MARTINAZZO, A. P.; DE FREITAS, W. K. Atuação dos restaurantes na logística reversa do óleo de cozinha no município de Volta Redonda/RJ. ENGEVISTA, V. 20, n.4, p.589-600, outubro 2018. 
SEBRAE. Minha Empresa Sustentável: Bares e Restaurantes. Centro Sebrae de Sustentabilidade. Cuiabá, 2016. 32 p.

SEBRAE/SC. Geração Millennials e Geração Z: Saiba como seus valores sustentáveis transformaram o consumo e as formas de trabalho. Santa Catarina, 2019. Disponível em: <https://atendimento.sebraesc.com.br/inteligencia/relatorio-de-inteligencia/geracoes-sustentaveis-conhecaos-valores-que-atraem-geracoes-y-e-z> Acesso em: 29 de outubro, 2020.

SEBRAE/SC. Práticas Sustentáveis: Como elas auxiliam o pequeno negócio em momentos de crise como a da COVID-19. Santa Catarina, 2020. Disponível em: <https://atendimento.sebrae-sc.com.br/inteligencia/relatorio-deinteligencia/praticas-sustentaveis-como-elas-auxiliam-o-pequeno-negocio-emmomento-de-crise > Acesso em: 29 de outubro, 2020.

SOLOMON, M. R. O comportamento do Consumidor - Comprando, Possuindo e Sendo. Porto Alegre: Bookman, 2011.

TORRESI, S. I. C.; PARDINI, V. L.; FERREIRA, V. F. O que é sustentabilidade?. Quím. Nova, São Paulo, v. 33, n. 1, p. 1, 2010.

VALENTE, J. Covid-19: Brasil tem 149 mil mortes e 5,05 milhões de casos acumulados. Agência Brasil, Brasília, 9 out. 2020. Disponível em: $<$ https://agenciabrasil.ebc.com.br/saude/noticia/2020-10/covid-19-brasil-tem-149mil-mortes-e-505-milhoes-de-casos-acumulados>. Acesso em 26 de out, 2020.

VICENZI, S. L.; POSSAN, E.; ANDRADE, D. F.; PITUCO, M. M.; SANTOS, T. O.; JASSE, E. P. Assessment of Environmental Sustainability Perception through Item Response Theory: a Case Study in Brazil. Journal of Cleaner Production, v. 170, p. $1369-1386,2018$. 